\title{
DIÁSPORAS, ETNICIDAD Y ETNOGÉNESIS: DE LAS REFLEXIONES TEÓRICAS A LOS ESTUDIOS DE CASO SOBRE LAS COMUNIDADES AFRO-DESCENDIENTES EN AMÉRICA LATINA
}

\section{Giselle INVERNON DUCONGE ${ }^{1}$}

Menara Lube GUIZARDI ${ }^{2}$

\begin{abstract}
Resumen
El presente artículo analiza las formulaciones teóricas sobre etnogénesis vinculándolas a poblaciones afro-descendientes en Latinoamérica. Empezamos recuperando características históricas del tráfico negrero y su influencia en la conformación de jerarquías raciales en países colonizados. Debatimos categorías teóricas como diáspora africana, etnicidad y etnogénesis, comprendiéndolas en el marco de la estructuración de los Estados-nación. Finalmente, revisamos algunos estudios de casos sobre procesos de etnogénesis afro-descendiente en cuatro
\end{abstract}

\footnotetext{
${ }^{1}$ Estudiante del Programa de Posgrado en Antropología del Instituto de Investigaciones Arqueológicas y Museo Gustavo Le Paige (IIAM). Universidad Católica del Norte (UCN, Chile) y Universidad de Tarapacá (UTA, Chile). Email: ginvernon@ucn.cl

2 Profesora del Departamento de Antropología de la Universidad Alberto Hurtado; Investigadora Asociada de la Universidad de Tarapacá (UTA, Chile). Email: menaraguizardi@yahoo.com.br
}

Fecha de recepción del artículo: Agosto 2014

Fecha de evaluación: Octubre 2014 
países de América Latina.

Palabras-clave: etnicidad, etnogénesis, raza, afro-descendientes, diáspora.

\begin{abstract}
The present paper analyzes the theoretical formulations regarding ethnogenesis. The discussion is connected with the review of case studies on afro-descendents in Latin America. We start recovering historical characteristics of the slave-trade and its influence in shaping racial hierarchies in colonized countries. We discuss theoretical categories such as African Diaspora, ethnicity and ethnogenesis understanding them in the context of the Nation-State formation. Finally, we will review cases studies of afro-descendent communities in four Latin-American countries.
\end{abstract}

Keywords: ethnicity, ethnogenesis, race, afro-decedents, Diaspora.

\title{
Résumé
}

Cet article analyse les formulations théoriques sur l'ethnogenèse en les reliant à des Afrodescendants en Amérique Latine. Commencé à se redresser caractéristiques historiques de la traite des esclaves et son influence dans la formation de hiérarchies raciales dans les pays colonisés. Nous discutons des catégories théoriques que la diaspora africaine, l'ethnicité et l'ethnogenèse dans la structure des états-nations. Enfin, nous passons en revue les études sur les processus d'ethnogenèse afro-descendant dans quatre pays d'Amérique Latine.

Mots-clés: ethnicité, ethnogenèse, race, Afro-descendants, diaspora.

\section{Introducción ${ }^{3}$}

El presente artículo tiene como objetivo debatir las formulaciones teóricas respecto de los procesos de etnogénesis con el interés de vincularlos a los actuales estudios sobre poblaciones afro-descendientes en contextos latinoamericanos. Nuestro análisis se constituirá

\footnotetext{
${ }^{3}$ El trabajo es parte de la investigación: “Afro-ariqueños: Rupturas hibridismos y continuidades de un proceso de etnicidad", desarrollada en el marco del Programa de Posgrado en Antropología del Instituto de Investigaciones Arqueológicas y Museo Gustavo Le Paige (IIAM, Chile), y patrocinada con fondos del Programa de Becas de Posgrado de la Universidad Católica del Norte (UCN, Chile).
} 
descriptivamente, estableciendo ejes de teorización y conceptos transversales a partir de la revisión de la literatura sobre afro-americanos en antropología social.

En un primero momento, discutiremos los trabajos de investigadores anglo-hablantes para, a continuación, acercarnos a los debates actuales en América Latina. Esto nos permitirá sentar bases teóricas para comparar los estudios de casos de comunidades afro-descendientes involucradas en procesos de negociación, redefinición y construcción de la identidad étnica en cinco diferentes contextos latinoamericanos.

Dividimos el texto en cuatro secciones subsecuentes a esta introducción. En el apartado segundo, presentaremos el debate sobre la construcción histórica de la presencia africana en Latinoamérica recuperando las características económicas, sociales y políticas del tráfico negrero y la influencia del sistema de uso de la mano de obra esclava en la conformación de ciertos juegos de alteridad y de clasificación étnico-racial de los afro-descendientes. Recuperamos este debate para señalar las estructuras de larga duración que persisten, reincidiendo en formas de discriminación originadas siglos antes, en el marco de la institucionalización del esclavismo en las colonias americanas.

Esta discusión nos permitirá plantear, en el apartado tercero, la configuración en los inicios del siglo XX, de dos lecturas antropológicas sobre la experiencia africana en las Américas; las cuales están genéricamente ilustradas como la oposición entre los argumentos de M. Herskovitz y F. Frazier. En este mismo apartado, y siguiendo el argumento de autores como K. Butler, E. T. Gordon, M. Anderson y K. Yelvington, debatiremos la emergencia del concepto de "diáspora africana" en antropología social, fundamentando a partir del mismo, el desarrollo de una interpretación sui generis sobre la construcción de los vínculos étnico-comunitarios de los afroamericanos.

En el cuarto apartado, para sedimentar nuestro análisis sobre el proceso de construcción colectivo-identitario y político de los afro-descendientes, conceptualizaremos etnicidad y etnogénesis entendiéndolas en el marco de los principios modernos de estructuración del Estado-nación: vinculadas a las relaciones de alteridad y a la constitución de jerarquías sociales. Simultáneamente, recuperaremos de Segato (1999) su crítica a la continuidad de las jerarquías de raza en América Latina y al carácter reproductor de las alteridades históricas del colonialismo que estas jerarquías manifiestan.

En el apartado quinto, analizaremos los procesos de etnogénesis afro-descendientes en América Latina como estrategias que conviven tensa y dialécticamente con la ruptura y reproducción de los sistemas de desigualdad y discriminación. Estos procesos emergen en un mundo que supuestamente ha globalizado el consumo de identidades "exóticas" a través del turismo y de la circulación de las "mercancías étnicas". Así, revisaremos y debatiremos estudios de caso 
realizados con comunidades de cinco diferentes contextos: los afro-venezolanos y afrocolombianos en su lucha de reconocimiento frente al Estado; las comunidades afrodescendientes de Esmeralda (Ecuador), de Centroamérica y de Amapá (Brasil).

\section{Afro-descendientes en América Latina: tráfico negrero y estructuras de larga duración}

La presencia africana en las Américas - del norte, del centro y del sur-, así como también en el Caribe, ha ocupado un lugar sustancial en los procesos de colonización, representando uno de los pilares económicos de la explotación colonial americana. Los primeros esclavos africanos llegaron a las Américas desembarcando en Puerto Rico en 1519 (Eltis, 2001:17), y el flujo esclavista no se detuvo hasta 1888 cuando Brasil ilegaliza el uso de mano de obra esclava africana ${ }^{4}$. Tenemos entonces casi cuatro siglos de flujos humanos entre África y Las Américas. Esta persistencia da cuenta de la importancia económica de la actividad en el marco del proceso colonial de las metrópolis europeas. La esclavitud negra fue una parte sustancial de los emprendimientos económicos de ingleses, franceses, holandeses, españoles y portugueses:

Los británicos (incluyendo las colonias británicas) y los portugueses suman siete de cada diez viajes de aprisionamiento de esclavos y han cargado cerca de tres cuartos de todos los esclavos embarcados en África. En general, los portugueses dominaron hasta antes de 1640 y después de 1807, y los británicos en los períodos intermedios a estas fechas. Los traficantes franceses, holandeses, españoles, daneses y estadunidenses aparecen como pequeños jugadores en comparación [con británicos y portugueses] pese a que en algunos momentos específicos, estos países asumieron importancia en el tráfico. (Eltis, 2001:20. Traducción propia).

Y pese a que gran parte de la historiografía internacional no lo haya reconocido como tal, la acumulación de capitales permitidos por las "industrias esclavistas" constituyó una de las formas primordiales de la acumulación económica moderna, siendo uno de los pre-requisitos para el desarrollo de la revolución industrial e incluso para la construcción del iluminismo europeo (Gilroy, 2002: 43-48). Este debate aparece ya en Marx (1996), en su análisis sobre los procesos primitivos de acumulación que han permitido la consolidación del modo capitalista de producción: actuando con niveles elevados de violencia a los cuales la historiografía y la economía política decimonónicas han sistemáticamente invisibilizado. Con su conocido tono irónico, Marx afirma que:

\footnotetext{
${ }^{4}$ Cuba y Brasil fueron los dos últimos países del globo en "erradicar", por lo menos jurídicamente, el esclavismo africano: Cuba en 1886 y Brasil en 1888 (Levine, 1989:202).
} 
La transformación de África en un campo cercado para la caza comercial a las pieles negras marca la aurora de la era capitalista de producción. Estos procesos idílicos son momentos fundamentales de la acumulación primitiva del capital (Marx, 1996: 370. Traducción propia, énfasis nuestro).

Así, la predominancia de los británicos como contrabandistas de africanos al Nuevo Mundo no es una casualidad: es parte sine qua non del proceso de acumulación que ha permitido a Inglaterra consolidar su dominio económico, años más tarde, en su revolución industrial. En relación a la América Española, este predominio de los británicos como distribuidores de esclavos africanos se hace notar especialmente entre los siglos XVI y XVIII, tras los tratados de paz firmados entre Inglaterra y España en Utrech (Tratado de Asiento). A partir de este acuerdo, Inglaterra gana el "derecho" de explotar el tráfico de negros entre África y las colonias españolas de las Indias occidentales, entregando a éstas un total de 4800 negros por año. El tratado permitió que los ingleses incrementasen paralelamente el contrabando de africanos, de manera que se supone que esta cuota de esclavos significase muy poco del total de seres vivos llevados por naves británicas a la América hispánica (Marx, 1996: 378).

Aquí, el proceso que genera la esclavitud africana en las América constituye el desenlace de un sistema mundo construido según jerarquías raciales que definen el locus geopolítico de los sujetos (Grosfoguel, 2006), en la misma medida en que constituyen su "alteridad" en relación a los europeos y a la centralidad normativa de la sociedad europea moderna (Dussel, 1994).

El tráfico de esclavos africanos hacia las Américas ha constituido uno de los tres grandes movimientos humanos de la era capitalista (Sutcliffe, 1998). Pese al esfuerzo de diversas generaciones de historiadores dedicados al tema, no sabemos exactamente cuántos seres humanos fueron víctima de este tráfico. La dificultad de cuantificar con exactitud se debe tanto a la invisibilización de la influencia e importancia africana en la construcción de la sociedad capitalista moderna (Patterson y Kelley, 2000:13; Gilroy 2002:17), como a la limitación de los registros históricos. Por otro lado, las embarcaciones en las cuales eran transportados desde África presentaban condiciones severamente precarias, de manera que entre un $15 \%$ y $25 \%$ de los sujetos no llegaban con vida a su destino (Lovejoy, 1982:481-491). De ahí que se estime que el número de personas efectivamente retiradas del continente sea bastante más relevante que el número de aquellas que aportaron al nuevo mundo. Se sabe, además, que Brasil fue el país receptor prioritario de africanos: aproximadamente 4 millones desembarcaron en el país entre los siglos XVI y XIX (Eltis, 2001:44). 
Asimismo, algunos autores establecen un intervalo que nos permite tener alguna dimensión de la brutalidad demográfica de la esclavitud. Sutcliffe (1998:57) estima que del siglo XVI al XIX, entre 10 y 20 millones de africanos fueron llevados al nuevo mundo en una "migración" que:

Respondió a las necesidades de varios grupos: los traficantes de esclavos, los dueños de las plantaciones en América y los caciques africanos que vendieron a los esclavos. Para los migrantes, la migración era totalmente obligatoria y puede suponerse que casi nunca respondió a sus propios deseos. Hoy persiste todavía la herencia de esta gran migración por lo que respecta a la estructura étnica de poblaciones, que influye en la realidad de la inmigración, sobre todo en América. (Sutcliffe, 1998:57).

Aquí surge pues el punto de partida de nuestro debate teórico. Este se refiere al uso de la expresión "migración" para denominar lo que Lovejoy (1992:473) definió como el desplazamiento humano forzoso más violento de la historia. Investigadores dedicados al estudio de los africanos y afro-descendientes en diferentes contextos en las Américas, han generado una especie de consenso sobre cómo definir este desplazamiento humano, prefiriendo el término "diáspora", al término "migración". En el apartado que sigue, debatiremos esta cuestión centrándonos en la emergencia del concepto de "diáspora" en los estudios sobre afroamericanos en antropología social.

\section{De la antropología de los afroamericanos a la antropología de la diáspora africana}

A inicios del siglo XX, se consolida en la antropología anglo-hablante un campo de estudios dedicado a la "antropología de los afroamericanos" (Herskovitz, 1948), y que desarrolló numerosos trabajos etnográficos sobre las comunidades afro-descendientes en diferentes contextos americanos (norte, centro y sur, además del Caribe). Este campo aparece a partir de la hegemonía boasiana en la antropología estadunidense, implementando en el debate una vigorosa crítica al racismo y biologismo con los cuales la antropología precedente teorizó estos grupos. El término "diáspora africana" en antropología social emerge a partir de los debates de esta escuela, conformándose curiosa y dialécticamente como parte de los procesos que recuperan a la vez que rompen con sus esquemas y preguntas teóricas.

Así, para introducir el término "diáspora" tenemos antes que remitirnos a la polémica surgida entre algunos investigadores en la primera mitad del siglo XX, y especialmente personificada en el debate entre Mellville Herskovitz y Frankie Frazier (Yelvington, 2001: 228). Estos autores centralizan formas supuestamente antagónicas de entender el desarrollo de la experiencia cultural, social e identitaria africana, cohesionando alrededor de sus escritos dos argumentos 
antropológicos divergentes en relación a los procesos de etnicidad e identidad afrodescendientes en el nuevo mundo.

Herskovitz es el etnógrafo a quién se atribuye el papel de haber legitimado el estudio de afrodescendientes en la antropología cultural estadounidense (Yelvington. 2001: 228) ${ }^{5}$, constituyendo un análisis que daba continuidad al particularismo histórico y cultural de Franz Boas, al cual él acentuó con una radical postura relativista (Gordon y Anderson, 1999: 285; Yelvington. 2001: 229). Con un amplio bagaje etnográfico -habiendo realizado trabajos de campo con comunidades afro-descendientes en Estados Unidos, Trinidad, Dahomey, Surinam, Haití y Brasil-, Herkovistz plantea la construcción de la etnicidad e identidad africana en las Américas como un proceso de supervivencia cultural, observando patrones de continuidad que remitían directamente a las "culturas africanas". Según su argumento, los africanos habrían conseguido resistir a la violencia del sistema esclavista, manteniendo instituciones sociales y culturales (religiones y prácticas religiosas; sistemas de organización familiar, lenguajes, etc.) traídas directamente de África. Estas formas culturales mantendrían diferentes niveles de conexión con las matrices culturales y sociales africanas, trayendo en sí "rastros" de estas matrices, a las cuales denominó "Africanismos" [Africanisms] (Herskovitz, 1948: 2).

Así, él plantea que la semejanza cultural-social entre afro-descendientes en diferentes puntos de América derivaba directamente de esta "preservación" parcial de formas étnicas originarias. Estos "Africanismos" conducirían el etnógrafo hacia el descubrimiento de las "esencias" que resistían debajo de la superficie de las prácticas actuales de las comunidades afro-descendientes. A través de ellas el etnógrafo podría no solamente medir la "intensidad" de la preservación de la práctica (su "autenticidad étnica africana"), sino también situar directamente su origen en las 'naciones' o etnias de África (Yelvington, 2001: 229). En síntesis, el argumento de Herskovistz incide en la comprensión de la existencia de una supuesta "esencia" cultural africana que, debido a la violencia de las sociedades esclavistas, sufrió procesos de adaptación, mestizaje y

\footnotetext{
${ }^{5}$ Se le atribuye este papel a partir de la publicación del libro "The Myth of Negro Past", de 1941 (Yelvington, 2001:228). Esta es la obra también que sienta un cierto nivel de consenso en la antropología en lo que se refiere a la oposición a la noción de que la especificidad afro-descendiente se aglutina alrededor de la construcción de raza (Gordon y Anderson, 1999: 285; Yelvington, 2001:228). A partir de Herskovitz, se establece que la afro-descendencia no consistiría "sencillamente en una entidad de raza, sino en una comunidad cultural que une dinámicamente África y las comunidades desplazadas a través de la experiencia común de prácticas y visiones de mundo africanas" (Gordon y Anderson, 1999: 285. Traducción propia).
} 
sincretismo ${ }^{6}$; perdiendo parte de una especificidad étnico-cultural que, no obstante, podría ser rastreada y "etnográficamente reconstruida".

Respaldados en estas postulaciones, y en gran medida influenciando y siendo influenciados por la obra de Herskovitz, antropólogos cubanos y brasileños desarrollarían, en el periodo entre guerras, la perspectiva de las continuidades africanas en el nuevo mundo (Patterson y Kelley, 2000: 15). Entre los cubanos, el nombre más conocido es el de Fernando Ortiz, cuya obra y actuación en la dirección del Centro de Estudios Afro-cubanos de La Habana marcaría el desarrollo de la etnografía sobre afro-descendientes en todo el mundo y el de Lydia Cabrera cuya producción textual es en la actualidad un archivo fundamental para religiosos y estudiosos de la cultura afrocubana. Entre los brasileños, Raymundo Nina Rodríguez, Arthur Ramos y Edison Carneiro, de la reconocida generación de "etnógrafos folcloristas" (Patterson y Kelley, 2000: 15). Habría que mencionar también al francés Roger Bastides, que circuló entre antropólogos cubanos y brasileños, produciendo importantes desarrollos etnográficos sobre las "continuidades" africanas (Bastides, 1972 y 1983).

En un sentido diverso, Frankie Frazier postulaba que la semejanza sociocultural entre los afrodescendientes en diferentes espacios de la Américas se debería no a la preservación esencialista de trazos de una etnicidad ontológica (e intacta) africana. Derivaría del hecho de que estos diferentes grupos fueron expuestos al mismo (y cruel) modo productivo esclavista. Frazier postulaba que no habría evidencias de que las "culturas originarias africanas" hubieran tenido una influencia directa en los desarrollos socioculturales en las colonias (Yelvington, 2001: $330)^{7}$. Afirmaba además que los africanos fueron sistemática y violentamente desprovistos de su patrimonio cultural (Frazier, 1939).

De ahí que las semejanzas entre afro-descendientes en Estados Unidos, Brasil, Caribe y en demás espacios donde su mano de obra esclava fue explotada, resultarían no de "continuidades", sino de un proceso de adaptación forzosa a un mismo tipo de contexto macroestructural. Las formas culturales y las prácticas sociales encontradas en estos colectivos serían ya resultado de un proceso de transformación étnica operado a partir del momento en que estos grupos pisaron suelo americano, pero desarrollado a lo largo de cuatro siglos. Según Frazier: “de África, nada permanece" (Yelvington, 2001: 332). En síntesis, el argumento postula que la

\footnotetext{
${ }^{6}$ Lo curioso, no obstante, es que el autor considerara que la improvisación y la resiliencia psicológica fueron ambas ya una profunda raíz cultural africana, de manera que las adaptaciones culturales en el nuevo mundo eran vistas, también ellas, como parte de la especificidad étnica de los afro-descendientes (Yelvington, 2001: 229).

${ }^{7}$ Sobre el tema, véase específicamente Frazier (1942).
} 
cultura y etnicidad afro-descendiente se constituye como un proceso radical de adaptación forzosa, operada tras la expropiación cultural-patrimonial de los africanos (que caracteriza su transformación en esclavos), y ocurriendo debido a un elevado nivel de violencia y ruptura social-comunitaria.

Estos dos autores, aunque adoptando posturas diversas, traen entre sí campos comunes y convergentes. Ambos han buscado solucionar la cuestión de por qué los afro-descendientes en diferentes puntos del continente americano experimentan ciertas prácticas culturales y sociales comunes. Ambos pusieron en prensa una postura ferozmente crítica a la violencia del esclavismo. No obstante, su legado sedimentó en los estudios antropológicos dos posturas encontradas. Por un lado, los "neo-Herskovitianos" y, por otro, los "teóricos del creacionismo o creolización" (Yelvington, 2001: 232). Los primeros postulan la supervivencia de rasgos de una etnicidad africana originaria en los afro-descendientes, mientras los segundos enfatizan la creatividad, adaptación cultural, y la etnogénesis constante entre estos grupos (Yelvington, 2001: 232). Una disputa que Patterson y Kelley (2000: 14) sintetizaron como la oposición teórica entre las "supervivencias" y las "transformaciones". Entre 1950 y 1960, toda una nueva generación de antropólogos daría seguimiento a este debate. William Bascom, Roger Bastide, Leonard Barrett, Sterling Stuckey, Joseph Murphy, Winifred Vass, y Joseph Holloway, desarrollarían etnografías que enfocarían las continuidades entre culturas afro-descendientes y culturas africanas; mientras Sidney Mintz y Richard Price enfatizarían las rupturas entre unas y otras (Patterson y Kelley, 2000: 16).

Paralelamente a este debate, a partir de 1950 el término "diáspora" empieza a ser usado (Patterson y Kelley, 2000: 15) por intelectuales pan-africanistas como Delaney, Blyden, Gamey, Du Bois, Padmore, para hablar de afro-descendientes (Gordon y Anderson, 1999: 284-285), Para estos autores, la identidad afro-descendiente sería:

Una construcción y adscripción de identidad racial fenotípicamente construida, indicativa de un origen territorial Subsahariano, y simultáneamente, una diferencia en relación a las populaciones de piel clara. Afuera de esta negritud 'racial', la membrecía al mundo negro estaba delimitada por experiencias comunes de terror racial y marginalización basadas en ideologías racistas de la inferioridad negra internacionalmente sostenidas. (Gordon y Anderson, 1999: 285. Traducción propia).

Según Gordon y Anderson (1999), esta generación de intelectuales no llegó a asumir las nociones de historia, consciencia de los orígenes y comunidad como fundadoras de la identificación diaspórica de los afro-descendientes. Este es un desenlace posterior, y que 
veremos consolidado entre 1980 y 1990, de la mano de autores como S. Hall, D. Scott y P. Gilroy, para quienes las teorías precedentes sobre las identidades negras se amparaban en esencialismos raciales y culturales y reinciden en categorías eurocéntricas acerca de la raza, cultura y no menos importante, del nacionalismo (Gordon y Anderson, 1999: 286). Operaban así lo opuesto de lo que proponían, resultando en "absolutismos étnicos que reificaban las propias categorías de opresión racial” (Gordon y Anderson, 1999: 286).

Desde los 90, no obstante, los estudios sobre las comunidades afro-descendientes en antropología social empezaron a manifestar la necesidad de deconstruir los esencialismos de estos referentes, superando la postulación de la etnicidad africana en las Américas como una supervivencia per se; a la vez que superando la noción de que se trataría de una invención totalmente americana, en la cual nada de África persistiría. Así, el término "diáspora" ha (re)emergido como categoría crítica que supera estos antagonismos postulando que efectivamente, algo de África se recupera, pero que esto se hace de manera contextual, histórica y profundamente interconectada con factores macro-estructurales que inciden inevitablemente sobre la vida de las comunidades afro-descendientes.

Según autores como Butler (2007), Gordon y Anderson (1999), y Yelvington (2001) el término "diáspora", remite también a entender la manera en como los sujetos y grupos afro constituyen activa y continuamente su sentido de pertenencia y arraigo grupal. Gilroy (2002) tuvo un importante papel en este giro conceptual, asumiendo que el término caracteriza a la "dispersión de personas africanas a partir de la esclavitud, la creación de culturas negras diferentes y aún así similares en el nuevo mundo, y el esfuerzo de imaginar un sentido compartido de comunidad en confrontación con sistemas persistentes de terror racializados" (Gordon y Anderson, 1999: 287. Traducción propia).

Para Butler, a su vez, compartir una identidad diaspórica sería la clave para entender cómo los grupos afro-descendientes generaron su sentido de etnicidad. En términos generales, el concepto de "diáspora" de la autora coincide con el de Gilroy, pero añade una dimensión en relación a la tierra de origen:

En primer lugar, el grupo de salida tiene dos o más destinos, creando, en lugar de la bipolaridad, la dispersión implícita en el término diáspora, que comparte el radical "spr" de la palabra griega diaspeirein ('dispersarse') (...). En segundo lugar, hay que mantener alguna relación con la tierra de origen [homeland], no importando si esta continúa o no a existir después de la dispersión diaspórica. En tercer lugar, debe haber una identidad común entre los del grupo diaspórico. Finalmente, la diáspora tiene que persistir por dos o más generaciones. (Butler, 2007:126. Traducción propia) 
Butler asume así que estos grupos, al imaginarse como parte de una experiencia diaspórica compartida, generan identidad y etnicidad de manera particular, siempre relacionando esta identidad a la idea de "homeland" (África). En este sentido, diferentes estudiosos sobre afrodescendientes han constatado la existencia de este elemento diaspórico como un rasgo estructurante de los procesos de etnicidad -Barnes-Harden (1984), Butler (2007), Gilroy (2002), Gordon y Anderson (1999), Gómez (2006), Ishibashi (2007), Lucena (2007), Palmer (2007) -. Así, la noción de diáspora se formula a partir de tres ejes críticos de teorización que inciden en la manera como los investigadores piensan actualmente los procesos de etnicidad afroamericanos:

- La crítica al foco culturalista. Las etnicidades afro-americanas derivan de la construcción de un sentimiento de pertenencia compartido que no constituye una forma cristalizada, sino un proceso que depende de la imaginación colectiva.

- La crítica a los esencialismos africanistas. Esta imaginación compartida devuelve un sentido de "africanidad" que no es una mera continuidad de lo que existe (o existió) en África, constituyendo procesos que reinventan la "tierra de origen".

- La crítica a la lectura reduccionista de los procesos comunitarios. La constitución del proceso de identidad diaspórica opera en consonancia con marcos estructurales -económicos y políticos-. Su comprensión requiere una lectura que historiciza el contexto, en la misma medida en que correlaciona los procesos comunitarios con procesos estructurales.

En el apartado que sigue, detallaremos "etnicidad" y "etnogénesis" dando cuenta de la importancia de la perspectiva diaspórica de las comunidades afro-americanas para el entendimiento de las transformaciones y apropiaciones identitarias que operan en los contextos globales actuales.

\section{Etnicidad y etnogénesis: claves para comprender la diáspora afroamericana en contextos (post)coloniales}

Partimos por definir que etnicidad y etnogénesis son términos polisémicos en las ciencias sociales, de manera que encontramos para ellos definiciones variadas y divergentes. Más que un problema de fondo, esta polisemia apunta al modo operandi de la investigación social, que a 
diferencia de los modelos paradigmáticos de las ciencias dichas "exactas" y "naturales", no generan consensos unidireccionales (Alexander, 1996: 29-32; Ianni, 1991: 204-207). La ausencia de consenso en lo que a etnicidad y etnogénesis se refiere es un indicio del debate permanente que enfrentan los diferentes conceptos en el pensamiento social. De ahí la necesidad de señalar que la etnicidad como concepto y como experiencia es siempre contextual, histórica, compleja, y que se hace difícil su reducción a conceptualizaciones universalistas ${ }^{8}$.

En términos históricos, lo que hoy se denomina etnicidad ha estado relacionado con el surgimiento y desarrollo del Estado-nación en la modernidad europea, entre los siglos XVI y XIX (Hobsbawn, 1998). La población de los recién surgidos Estados-nacionales era heterogénea en la mayoría de los casos. El origen de los grupos étnicos internos a las naciones era muy variado, especialmente considerando que las regiones se despoblaron y repoblaron a lo largo del tiempo, y que se mantuvo una movilidad demográfica muy relevante previa y posterior al establecimiento de las fronteras nacionales. Así, la invención política del Estado-nación se da a la par de la invención de las mitologías de "homogeneidad" (étnica, cultural, social y política) interna a los Estados. Pero, en términos académicos, la categoría solamente emerge en la sociología y antropología a mediados del siglo XX, recuperando un uso semántico que nace vinculado a las conceptualizaciones sobre raza:

La primera vez que se registra el uso del término 'etnicidad' es en 1953, por parte del sociólogo norteamericano David Reisman. No obstante, el término 'étnico' es mucho más antiguo; deriva de la voz griega 'ethnos' -que a su vez deriva del término 'ethnicus'-, que originalmente significaba 'pagano'. En el idioma inglés fue empleado de esta manera desde la mitad del siglo XIV hasta la mitad del siglo XIX, cuando gradualmente comenzó a hacer referencia a características raciales. (Informe Nacional de Desarrollo Humano, 2004:6).

Giménez (2006: 129), apoyándose en el trabajo precedente de Glazer y Moynihan (1975), concuerda con el dato de que la utilización antropológica del término "etnicidad" sería una contribución original de Reisman, reconociendo por otro lado que algunos los atribuyen a W.L. Warner. Sobre el origen griego de la expresión, Giménez (2006: 129-130) aclara que:

\footnotetext{
${ }^{8}$ Al respecto Souza Santos (2009) afirma: "la ciencia social (...) tiene que comprender los fenómenos sociales a partir de las actitudes mentales y del sentido que los agentes le confieren a sus acciones, para lo que es necesario utilizar métodos de investigación y hasta criterios epistemológicos diferentes a los existentes en las ciencias naturales, métodos cualitativos (...) con vistas a la obtención de un conocimiento intersubjetivo, descriptivo y comprehensivo" (Souza Santos, 2009:30).
} 
(...) El uso de estos dos últimos términos [etnia y ethnos] casi siempre ha tenido una connotación excluyente, discriminatoria y la mayor parte de las veces inferiorizante. Es decir, las 'etnias' siempre son los 'otros', menos el grupo que clasifica de este modo a esos 'otros' desde una posición dominante. (...)En latín, la traducción de ethnos es natio, pero este término también designa sólo a los pueblos bárbaros y lejanos, por oposición a los romanos que se auto-clasificaban como populus, y nunca como natio. (...)Las observaciones precedentes vienen a cuento, porque parece persistir hasta nuestros días este sesgo etnocéntrico del término 'etnia' y sus derivados, que tiende a infiltrarse subrepticiamente incluso en el uso científico de los mismos siguiendo la fórmula.

Se establece una relación directa entre el término "étnico" con lo que se entendía como "racial" a partir del siglo XIX. En este período, las diferencias visibles en el físico pasan a entenderse como demasiado evidentes para ignorarlas y con excesiva frecuencia éstas fueron utilizadas para señalar o reforzar las distinciones entre "nosotros" y "ellos", incluyendo las distinciones nacionales (Hobsbawn, 1998:74). Desde esa época a la fecha ha sido corriente el uso de ambos términos, raza o etnia, casi siempre relacionándose con el origen y descendencia comunes de un grupo o colectivo humano. Hay cierto consenso en cuanto a que los "grupos étnicos" generalmente presentan algunos rasgos culturales "cristalizados" que los caracterizan. Según Hutchinson y Smith:

Un nombre propio, que identifica y expresa la 'esencia' de la comunidad que denomina. 2. Un mito acerca de la existencia de un ancestro común, e incluye la idea de un origen común, en tiempo y lugar, que le da al grupo un sentido de parentesco y de pertenencia a "una familia mayor". 3. Una memoria histórica compartida, o memorias compartidas de un pasado común, incluyendo héroes, eventos y su conmemoración. 4. Uno o más elementos de una cultura común, que no necesita ser especificada pero que incluye generalmente a la religión, las costumbres y tradiciones y el idioma. 5. Un vínculo con una tierra natal/ancestral, aunque no necesariamente implica ocupación física; es suficiente la conciencia del vínculo simbólico con ella. 6. Un sentido de solidaridad de parte, cuando menos, de algunos segmentos de su población (Eriksen, 1996:28).

Hasta 1970, la antropología social reprodujo una categorización "culturalista y sustancialista" acerca de la etnia, como si entre ella y la identidad étnica hubiera una "correspondencia predecible y sistemática" (Giménez, 2006: 132). En los 70, esta reificación de una sustancia cultural contenida por la identidad étnica fue desafiada por tres teóricos: E. Leach, M. Moerman y F. Barth (Giménez, 2006: 133). Para ellos, más que la cristalización de un contenido cultural, la etnia resultaría del proceso de determinación recíproca de los grupos culturales. La interacción entre los grupos constituiría el mecanismo sine qua non de la propia etnicidad. Ésta, 
a su vez -más allá del "clásico" isomorfismo espacio-cultura con que la antropología teorizó a los grupos étnicos (Gupta y Fergunson, 1992 y 1997)- tendría su existencia dada por desplazamientos espaciales-sociales, marcados por: la desigualdad (relación centro periferia en el sistema mundo), la movilidad (migración) y los cambios geopolíticos (decolonización) (Giménez, 2006: 133).

El foco analítico en la antropología se desplazó de la atención hacia la caracterización descriptiva de los grupos a la atención hacia los procesos sociales de construcción de la experiencia identitaria (Giménez, 2006: 133). Según Cohens, etnicidad pasaría a representar, "un concepto flexible de adjudicación, clasificación y delimitación el que está en un constante proceso de modificación dependiendo de las situaciones concretas" (Rossbach, 2009:204).

Ya a fines de los 80 , se consolidó una pluralidad de posturas críticas que relativizaron el uso antropológico de la etnicidad, incluyendo en este debate la perspectiva de pensadores latinoamericanos ubicados en la "otredad" étnica y normativa de la ciencia anglo-sajona. Entre ellos, recuperamos específicamente a Segato y Grosfoguel, cuyos argumentos nos permiten establecer una vinculación directa entre la etnicidad, las jerarquías de raza, el nacionalismo y la experiencia subalterna de colonialidad en América Latina.

Según Segato (1999), las categorías étnico, etnicidad y sus variantes fluyen en el marco de las naciones y son usadas como fundamentos que soportan el racismo colonial que persiste, permaneciendo como paradigmas reduccionistas de una ciudadanía de segunda clase, subordinada y adscripta, a manera de minorías culturales recién llegadas a la "nación imaginada".

Desde la perspectiva de Grosfoguel (2006: 69), todas las identidades modernas resultan de la "construcción de la colonialidad del poder en el mundo moderno/colonial", y "su defensa no es tan subversiva como podría parecer a primera vista. Las identidades 'negra', 'indígena', 'africana' o las nacionales como la 'colombiana', 'keniana' o 'francesa' son construcciones coloniales". El autor profundiza acerca de la persistencia de las clasificaciones étnico-raciales como formas eurocéntricas de dominación que reproducen la colonialidad global, pese a la casi desaparición de la misma en términos jurídicos.

Así, etnicidad y raza serían formas de control político y económico inherentes al colonialismo. $\mathrm{Su}$ persistencia tiene que ver con el sometimiento de ciertos grupos a los procesos del capitalismo avanzado: "desde la formación inicial del sistema mundo capitalista, la incesante acumulación de capital estuvo imbricada con ideologías globales racistas, homofóbicas y sexistas" (Grosfoguel, 2006:61).

A partir de estas consideraciones críticas podemos dimensionar mejor la forma en que la "etnogénesis" viene siendo trabajada. En relación al concepto, encontramos referencias en 
trabajos de diferentes autores, como Barreto (1994), Bartolomé (2003), Stallaert (2012), Gomes (2011), Gómez (2006), Ishibashi (2007), Lucena (2007), Mohr (2007), entre otros. Según Bartolomé, la etnicidad puede ser definida como "el surgimiento de nuevas comunidades que se designan a sí mismas en términos étnicos, para diferenciarse de otras sociedades o culturas que perciben como distintas a su autodefinición social" (Bartolomé, 2003:174). La etnicidad conllevaría entonces directamente al principio de etnogénesis, dado que la primera se constituye como proceso comunitario de auto-identificación que implica, eminentemente, la transformación y re-invención identitaria.

Stallaert concordará con parte de esta noción asumiendo el carácter procesual de la etnicidad y definiendo la etnogénesis como "formación y transformación de las identidades étnicas" (Stallaert, 2012:272). Caminamos pues a la comprensión de que la etnicidad, más que una forma dada o natural, conlleva un proceso de transformación etnogénico, constituyendo a la par procesos sociales de identificación y expresando la emergencia de nuevas identidades asumidas como fundamentales por sus actores, dentro de contextos socioculturales en los que se mantienen fronteras entre grupos percibidos como diferentes-. Destacamos así la dimensión e impacto político de estos movimientos de creación, puesto que a partir de ellos "emergen demandas de inclusión en el seno de los Estados-nacionales por parte de los sectores excluidos, cada una de estas demandas, en el nombre de una identidad muchas veces retocada o incluso construida para poder servir de rúbrica al sujeto de esa demanda" (Segato, 2007:15).

La reemergencia étnica o etnogénesis en países colonizados, involucraría un esfuerzo de relectura de las memorias compactadas o fracturadas, de historias contadas desde un solo lado y que suprimieron otras memorias invisibilizadas por siglos de dominación (Segato, 2007). Consecuentemente, el estudio de las etnicidades en la actualidad, conllevaría a la reconstrucción de los procesos históricos de alteridad vividos en el marco de la experiencia colonial latinoamericana. Estos fenómenos demandan una mirada que considere que la identidad étnica es dinámica: mutable y reinventada. Debido a los cambios que experimenta y a la historicidad de estos cambios, la etnicidad se constituye como forma flexible y adaptable a las circunstancias. Consecuentemente, más allá de todo esencialismo, la etnicidad está históricamente determinada.

Esto no quita que las personas, las colectividades e incluso el Estado, la vean como algo dado, o la enuncien así en confrontaciones político-sociales. Existe, una tendencia por parte del Estado de reificar la etnicidad, cristalizándola como algo estático, percibiendo los grupos étnicos internos como "sin historia", como "parados en el tiempo". Se reproduce así una ideología etnocéntrica, una herencia de la modernidad europea (Dussel, 1994), según la cual todo lo que no es urbano, capitalista, "occidental", no tiene historia. Muchos grupos indígenas y afro- 
descendientes en Latinoamérica han tenido que representarse como "el otro étnico" frente al Estado para ser reconocidos como colectividad (como "minoría étnica"). Teniendo que "inventar tradiciones" y cosificar su cultura e identidad como si esta no estuviera en movimiento?.

En países nacidos de la conquista y colonización, las transformaciones culturales que incluyen la producción y reproducción de identidad, representan una característica recurrente en la persistencia de la desigualdad, pues:

Aparentemente el origen étnico racial influye de manera importante en la posición que ocupan las personas dentro de la estructura social, siendo la discriminación y la exclusión los mecanismos a través de los cuales un grupo dominante mantiene y justifica la subordinación social y económica de otros, reproduciendo y perpetuando la inequidad (Bello y Rangel, 2002:40).

Consecuentemente, en Latinoamérica, la discriminación y el racismo son parte esencial de los problemas regionales, que han potenciado la pobreza, la exclusión y la desigualdad de millones de personas entre los que se encuentran los indígenas y afro-descendientes. Las etnogénesis observadas actualmente en este contexto dialogan activamente con esta dimensión histórica de la desigualdad étnico-racial.

\section{Estudios de caso de la etnogénesis afro-descendiente en América Latina}

Actualmente, existen estudios sobre comunidades latinoamericanas que se auto reconocen como afro-descendientes y que vienen experimentando procesos de reemergencia étnica. La revisión crítica de estos ejemplos provee un estado del arte que permite establecer el diálogo entre los conceptos teóricos hasta aquí debatidos, y su aplicación a contextos específicos en América Latina.

Un primer ejemplo son las investigaciones de Gómez (2006), centradas en experiencias de colectivos y organizaciones afro en Esmeraldas (Ecuador) y en Cali (Colombia). La autora se

${ }^{9}$ Según Hobsbawn (2002) el surgimiento de los Estados-nacionales provocó una presión en cuanto a dicha "invención". El autor define el uso del término "tradición inventada" como aquella que implica: ...un grupo de prácticas, normalmente gobernadas por reglas aceptadas abierta o tácitamente y de naturaleza simbólica o ritual, que buscan inculcar determinados valores o normas de comportamiento por medio de su repetición, lo cual implica automáticamente continuidad con el pasado. De hecho, cuando es posible, normalmente intentan conectarse con un pasado histórico que les sea adecuado (Hobsbawn, 2002:8). 
encarga de explicar cómo se entiende la construcción identitaria y la emergencia de políticas en ambas ciudades, enfatizando el papel central de la producción de identidades y políticas culturales.

Gómez, por otro lado, recupera la marginalización de los afro-descendientes en estos contextos, observando cómo la comunidad "ha estado sumida en la subalternización de las políticas locales (...) pese a que gran parte de su población es negra" (Gómez, 2006:12). Se resalta que la etnicidad de ambas comunidades fue construida desde la llegada de los afro-pobladores a las dos ciudades, Sus expresiones identitarias -silenciadas hasta hace muy poco- hoy potencian y resignifican las prácticas, formas de hacer y de entender alternativamente la dimensión política de la cultura. Es importante tener en cuenta además, que la etnogénesis afro-colombiana tiene lugar como resultado de "una dinámica en que la coyuntura política, los contactos y el intercambio interétnico y un Estado-nacional con necesidades de reformarse coinciden y crean innovaciones inesperadas" (Rossbach, 2009: 214). Tenemos así un movimiento de reetnificación que parte de las comunidades hacia el Estado, pero también, y en gran medida, del Estado hacia las comunidades.

Con respecto al caso afro-venezolano podemos mencionar los trabajos realizados por Ishibashi (2007) y Lucena (2007). Ambos coinciden en que la sociedad venezolana vive un proceso de etnogénesis asociado a su comunidad de afro-descendientes. Ishibashi (2007) describe la racialización del conflicto político en Venezuela, bajo el gobierno de Hugo Chávez. Paradójicamente, en este período se promulgó el ideal constitucional de la refundación multiétnica y pluricultural del país, sirviendo de plataforma a las comunidades afrodescendientes para exigir su reconocimiento en el marco de la nación. En todo caso:

El credo multiétnico y pluricultural quedó incompleto, ya que la población afro en Venezuela no logró ser reconocida como parte de la diversidad étnica del país, a pesar de la propuesta que hicieron algunas organizaciones civiles (las cuales se integrarían luego a la Red de Organizaciones Afro-venezolanas: ROA) para dar visibilidad constitucional a los afro-descendientes en Venezuela. En cuanto a la 'refundación' multiétnica del país, la Venezuela bolivariana se encuentra en mora en comparación con países vecinos como Nicaragua, Brasil, Colombia y Ecuador, los cuales incluyeron a la población afro en la Carta Magna durante las últimas dos décadas como parte de su nacionalidad. (Ishibashi, 2007:26).

En los trabajos de Lucena (2007), se profundiza en la lucha de los afro-venezolanos por el reconocimiento constitucional pleno. El estudio da a conocer el papel que desempeña la Red de Organizaciones Afro-venezolanas en la resignificación étnica en el contexto "bolivariano". Identifica los logros relacionados al reconocimiento de derechos de dicha comunidad y 
menciona las dificultades que propiciaron que estos derechos no se hayan materializado en la práctica. Así, "el Estado hegemónico ha mostrado una vasta incomprensión en torno al significado de condición, dignidad y derechos humanos de este colectivo" (Lucena, 2007:59); obedeciendo a una lógica de visibilidad limitada de los históricamente invisibles ${ }^{10}$. Lucena coincide con lo que analiza Segato (2007) para el caso brasileño, observando que se integran a los afro-descendientes, asumiéndose sus prácticas culturales, como parte fundamental de la identidad nacional. Esto no quita que el racismo institucional continúe existiendo de manera muy marcada, ya que a pesar de la integración de los afros, no se les da condiciones económicas y políticas igualitarias a las concedidas a los considerados "blancos". Esto institucionaliza en Brasil aquello que Da Matta (1981) denominó la fábula, y que Ortiz (2003) denominaría el mito de la democracia racial brasileña. La misma consideración aparece antes, no obstante, en Florestan Fernandes (1972).

Lucena (2007) propone ir en pos de la construcción de un nuevo imaginario político que haga puente con esa concepción del tiempo mítico y social de los ancestros africanos y su descendencia; haciendo referencia a uno de los elementos presentes en el concepto de diáspora discutido anteriormente: la idea de África como "homeland" común:

La historia de África y su diáspora tiene innumerables fórmulas de organización sociopolítica, hay que ir a la consulta de los ancianos, de los hombres y mujeres que dialogan con sus ancestros, consultar a los maestros que aún viven, estructurar alianzas regionales nacionales e internacionales $\mathrm{y}$, sobre todo, evitar el caos o desorden, el distanciamiento o deserción de sus integrantes (Lucena, 2007:66).

Gomes (2011), a su vez, expone elementos sobre procesos históricos de etnogénesis en las fronteras amazónicas, especialmente entre Brasil, Surinam y Guayana Francesa. Asume que "en áreas de fronteras, podemos pensar procesos de etnogénesis a través de la formación de comunidades de fugitivos y de trabajadores -africanos e indígenas de varias procedencias étnicas- de las reducciones, haciendas y misiones" (Gomes, 2011:642). Se apoya para esto en registros históricos -coloniales y postcoloniales- que dan fe de movimientos migratorios de diferentes grupos, entre ellos los afro-descendientes, y considera las conexiones culturales que son observables a través de las narrativas surgidas de la interrelación entre diferentes grupos; así como de las imágenes y pugnas translocales que se generan en esta región fronteriza. Dichos

10 Según la autora: "Esta lógica otorga reconocimientos pero no valida derechos. Da paso a una demostración de intencionalidades que no se materializan en políticas de Estado” (Lucena, 2007:62) 
procesos se dan desde el siglo XVII y llegaron hasta nuestros días:

En diferentes partes de la extensa Amazonía -especialmente donde había reducciones y organización del trabajo obligatorio, además de vínculos económicos- hay registros sobre el aumento de fugas y el establecimiento de fugitivos en nuevas comunidades, en un proceso de etnogénesis aún poco conocido. (Gomes, 2011:632).

Con respecto a este patrón persistente de movilidad, Gomes menciona a los Karífuna, grupo que surgió de las experiencias de los contactos interétnicos en los siglos XVII y XVIII en el estado brasileño de Amapá. Grupos indígenas como los Waiãpi, que actualmente cuentan con un área demarcada también en Amapá, registran en sus narrativas orales las disputas entre los franceses y portugueses así como la construcción de fortalezas militares, alianzas y conflictos derivados. En sus memorias, se refieren a los grupos de negros con los que entraron en contacto:

En lo que se refiere al norte amazónico y sus fronteras transnacionales tenemos que reflexionar -al hablar de 'mezclas'- quiénes eran 'indios' o 'negros' y donde se parecen en las narrativas coloniales y postcoloniales. Podemos pensar en la constitución de grupos étnicos, sus percepciones y expectativas en torno a los contactos, el territorio, el ecosistema y las cosmologías reinventadas (Gomes, 2011:642).

Gomes (2011) apunta a algo fundamental para las zonas de frontera: la necesidad de entender los procesos de etnogénesis en estos territorios como conflictivos desde períodos coloniales. Estos procesos llegan al periodo de construcción de las naciones en Latinoamérica -cuya efervescencia se concentra en el siglo XIX- con una complejidad que precede al establecimiento de las fronteras nacionales. Habría que observar entonces, cómo estos procesos alteran y son alterados por la construcción de los paradigmas étnicos nacionales (Segato, 2007), los cuales forman parte del proceso de invención de la identidad nacional de los países.

Siguiendo a los procesos de etnogénesis, pero ahora en Centroamérica, nos encontramos las investigaciones de Mohr (2007) realizadas sobre los Garínagu ${ }^{11}$. Esta población afro-caribeña, a pesar de los procesos de urbanización y las constantes migraciones en pleno siglo XX, sobre todo a los Estados Unidos, han mantenido procesos de transmisión de sus prácticas, actualizando una cohesión grupal alrededor de ellas, un sentimiento de auto-reconocimiento del grupo a través de la transmisión de las prácticas culturales a nuevas generaciones. Los ciclos de

${ }^{11}$ Etnia de descendencia afro-amerindia, que vive desde el principio del siglo XIX en la costa atlántica de Belice, Guatemala, Honduras y Nicaragua. 
fiestas culturales de este pueblo viven procesos de cambio casi permanentes. Los Garínagu siempre han sabido integrar nuevos elementos en su cultura y transmitirlos de generación en generación, como tradición. Según Mohr es posible que "esta habilidad de la sociedad Garífuna, de integrar nuevos elementos culturales y al mismo tiempo conservar cierto etnocentrismo pragmático, pueda explicar su existencia con una fuerte identidad cultural hasta nuestros días" (Mohr, 2007:82).

\section{Consideraciones finales}

Tomando estos casos específicos en consideración, encontramos que la realidad en los diferentes contextos latinoamericanos plantea un desafío a ciertas categorías antropológicas. Los estudios de caso que hemos brevemente sintetizado informan sobre cómo las comunidades afrodescendientes estudiadas van tomando conciencia de la necesidad de formular proyectos identitarios propios, que resultan contra-hegemónicos, pero que en algunos momentos son enunciados o presentados al Estado como recursos para construir o refundar la nación. La complejidad de estos procesos de etnogénesis está, por lo tanto, históricamente vinculada a la incorporación desigual de estos grupos a la propia nación. En algunos casos, se les devuelve a los grupos cierto derecho de pertenencia al cuadro identitario nacional; pero esto ocurre solamente en la medida en que ellos reconocen su diferencia en cuanto hijos e hijas de una "diáspora africana". Así, en estos casos de reemergencia étnica afro-descendiente "es la estructura segmentada de la diferencia que se desarrolla a partir del modelo fundador blancosnegros como matriz rectora e idioma de la alteridad y de la producción de identidad" (Segato, 1999:127), lo que distingue y problematiza al proceso de etnogénesis.

La globalización ha provocado el surgimiento de identidades culturales y étnicas para el consumo, lo que es fundamental para entender el actual surgimiento del mercado turístico internacional. En este sentido, hay una búsqueda por parte de los Estados encaminada a identificar y potenciar los grupos que pueden configurar sus identidades como forma de venta para el mercado turístico; poniendo énfasis en posibles mercancías exóticas que tengan un público consumidor global. Entre los principales productos, se encuentran las artesanías, ropas, comidas, bailes y artes-étnicos. Se puede decir entonces que la fuerte re-etnificación incentivada por el Estado colombiano que relata Gómez (2006) no constituye un proceso aislado, sino que responde a tendencias del capitalismo avanzado global $^{12}$.

12 Según Gómez (2006) existe en Colombia un movimiento desde el Estado para incentivar el reconocimiento y el auto-reconocimiento de grupos afro. Esta necesidad, no obstante, tiene que ver con 
Al mismo tiempo, y dialécticamente, no se trata solamente de un proceso de imposición del mercado global y del Estado hacia los grupos, obligándoles a "etnificarse". Los mismos grupos se apropian de esto, y pasan a dirigir su etnogénesis. Es decir, pasan a producir su "presentación" como grupo étnico, que va de la mano con las expectativas de consumo global, en este caso de los turistas, principalmente. Comaroff y Comaroff (2011) que observan procesos de dominación y de liberación simultánea y dialécticamente confundida en los grupos étnicos de África afirman que la etnicidad como empresa está en auge y que:

la industria de la identidad es un ejemplo muy revelador de esa tensión múltiplemente mediada entre lo universal y lo particular. El etnocomercio alimenta un modo de producción y reproducción cada vez más ubicuo, nacido de una época en la que la venta de la cultura ha sustituido la venta del trabajo en muchos lugares. (Comaroff y Comaroff, 2011:45).

Cabría preguntarse si la intensificación de los movimientos de etnogénesis afro-descendientes, y su creciente aparición a partir de movimientos artísticos culturales, no es una estrategia de este tipo orientada a generar una etnicidad que permita que los sujetos sitúen su especificidad étnica no solamente en el marco del mercado global y globalizado. Sino también en los procesos de diálogo con el Estado. Esta interrogante es la que debe, en los actuales contextos latinoamericanos, acompañar la manera en como revisitamos los conceptos de diáspora y etnicidad en antropología social.

\section{Referencias Bibliográficas}

ALEXANDER, J.C (1996): A importância dos Clássicos. En Teoria Social Hoje. Giddens, A. y Turner, J. (EDS.) Editora Unesp. São Paulo.

BARTOLOMÉ, M.A (2003): “Los pobladores del 'Desierto' genocidio, etnocidio y etnogénesis en la Argentina" - Cuadernos de Antropología Social - 17 (págs 162-189).

BASTIDE, R (1972): African Civilisations in the New World - Hurst - Londres.

los procesos de globalización que han transformado las identidades culturales y étnicas en un producto más, entre los que circulan en la esfera global. La etnicidad afro-colombiana es potenciada en la medida en que puede expresarse como un objeto exótico de consumo: un producto a ser apreciado en cuanto "autenticidad cultural". 
BASTIDE, R (1983): Estudos Afro-brasileiros - Perspectiva - São Paulo.

BELLO, A.; RANGEL, M. (2002): "La equidad y la exclusión de los pueblos indígenas y afrodescendientes en América Latina y el Caribe" - Revista de la CEPAL - 76 (págs 39-54).

BUTLER, K.D (2000): "From Black History to Diasporan History: Brazilian Abolition in AfroAtlantic Context" - African Studies Review - 43(1) - (págs 129-139).

COHEN, R(1979): "Ethnicity: Problem and Focus in Anthropology" - Annual Review of Anthropology - 7 - (págs 379-403).

COMAROFF, J y COMAROFF, J(2011): Etnicidad S.A. - Katz Editores - Madrid.

DA MATTA, R (1981): Relativizando - Vozes - Petrópolis.

DUSSEL, E (1994): 1492: El encubrimiento del Otro. Hacia el origen del mito de la modernidad-Plural Editores - La Paz.

ELTIS, D (2001): The Volume and Structure of the Transatlantic Slave Trade: A Reassessment - The William and Mary Quarterly - 58(1) - (págs 17-46).

ERIKSEN, T (1996): "Ethnicity, Race, Class and Nation" en Ethnicity - Hutchinson, J. y Smith, A. (EDS). OUP - Oxford.

FERNANDES, F (1972): O Negro no Mundo dos Brancos - DIFEL - São Paulo.

FRAZIER,E.F (1939): The Negro Family in the United States - University of Chicago Press Chicago.

FRAZIER, E.F(1942): “The Negro family in Bahia, Brazil” - American Sociological Review 7(4) - (pág 465-78).

GILROY, P(2002): The Black Atlantic. Modernity and Double Consciussness - Verso Londres. 
GIMÉNEZ MONTIEL, G (2006): "El debate contemporáneo en torno al concepto de etnicidad" - Cultura y Representaciones Sociales - 1(1) - (pág 129-144).

GLAZER, N. y MOYNIHAN, D (1975): Ethnicity: Theory and Experience - Harvard University Press - Cambridge.

GOMES, F(2011): "Etnogénesis en las fronteras entre Brasil, Surinam y Guayana Francesa, siglos XVII-XX: más aproximaciones” - Antíteses - 4(8) - (pág 631-644).

GÓMEZ, C (2006): Identidades y políticas culturales en Esmeralda y Cali. Estudio De Casos Sobre Organizaciones Afro, Producción Cultural y Raza. Tesis defendida en el Programa de Maestría en Estudios de la Cultura. Mención en Políticas Culturales - Universidad Andina Simón Bolívar - Ecuador.

GORDON, E.T y ANDERSON, M (1999): “The African Diaspora: Toward an Ethnography of Diasporic Identification" - The Journal of American Folklore - 112(445) - (pág 282-296).

GROSFOGUEL, R. (2006): “La descolonización de la economía política y los estudios postcoloniales: transmodernidad, pensamiento fronterizo y colonialidad global" - Notas de Población - 80 - (pág 53-74).

GUPTA, A. y FERGUSON, J (1992): "Beyond 'Culture': Space, Identity, and the Politics of Difference” - Cultural Anthropology - 7(1) - (pág 6-23).

GUPTA, A. y FERGUSON, J (1997): "Discipline and Practice. 'The Field' as Site, Method, and Location in Anthropology". en Anthropological Locations. Boundaries and Grounds of a Field Science - Gupta, A. y Ferguson, J. (EDS) - University of California Press - Berkeley-Los Angeles.

HERSKOVITS, M.J (1941): The Myth of the Negro Past - Harper - New York.

HERSKOVITS, M.J (1948): "The contribution of Afro-Americans Studies to Africanist Research" - American Anthropologist - 50(1) - (pág 1-10).

HOBSBAWN, E (1998): Naciones y nacionalismo desde 1780 - Crítica - Barcelona. 
HOBSBAWM, E (2002): “Introducción: la invención de la tradición" - en La invención de la Tradición, Hobsbawm, E. y Range, T (EDS) - Crítica - Barcelona.

IANNI, O (1991): “A crise dos paradigmas na Sociologia” - Revista Crítica de Ciências Sociais - 32 - (pág 195-215).

ISHIBASHI, J (2007): “Multiculturalismo y racismo en la época de Chávez: Etnogénesis afrovenezolana en el proceso bolivariano" - Humania del Sur - 2(3) - (pág 25-41).

LEVINE, R. M (1989): "Review: Turning on the Lights: Brazilian Slavery Reconsidered One Hundred Years after Abolition” - Latin American Research Review - 24(2) - (pág 201-217).

LOVEJOY, P.E (1982): "The Volume of the Atlantic Slave Trade: A Synthesis" - The Journal of African History - 23(4) - (pág 473-501).

LUCENA, H. (2007): "Consideraciones sobre el movimiento social afro-venezolano" Humania del Sur - 2(3) - (pág 59-72).

MARX, K (1996) - A assim chamada Acumulação Primitiva - en O Capital Volumen II, Marx, K. - Editora Nova Cultural, São Paulo.

MOHR, M (2007): "Los garínagu en Centroamérica y otros lugares. Identidades de una población afro-caribe entre la tradición y la modernidad" - Indiana - 24 - (pág 67-86).

ORTIZ, R (2003): Cultura Brasileira e Identidade Nacional - Brasiliense - São Paulo.

PATTERSON, R.T y KELLEY, R.D.G (2000): "Unfinished Migrations: Reflections on the African Diaspora and the Making of the Modern World" - African Studies Review - 43(1) - (pág 11-45).

ROSSBACH, L (2009): “QQué pasa con el Pacífico Negro en el Atlántico Negro? El Atlántico Negro de Paul Gilroy frente a los acontecimientos (afro) colombianos" - Memorias - 6(11) (pág 199-219). 
SEGATO, R.L (1999): "Identidades políticas/ Alteridades históricas: Una crítica a las certezas del pluralismo global" - Maguaré - 14 - (pág 114-147).

SEGATO, R.L (2007): La nación y sus Otro: Raza, etnicidad y diversidad religiosa en tiempos de Políticas de la identidad - Prometeo - Buenos Aires.

SOUZA SANTOS, B (2009): Un discurso sobre las ciencias - en Epistemologías del Sur Souza Santos, B - CLACSO - Buenos Aires.

STALLAERT, C (2012): “Traducción y conversión como modos de creación de identidades contra-hegemónicas. El caso de las culturas ibéricas" - Mutatis Mutandis - 5(2) - (pág 271283).

SUTCLIFFE, B (1998): Nacido en otra parte. Un ensayo sobre la migración internacional, el desarrollo y la equidad - Hegoa - Bilbao.

YELVINGTON, K.A (2001): "The Anthropology of Afro-Latin America and the Caribbean: Diasporic Dimensions" - Annual Review of Anthropology - 30 - (pág 27-260). 